\title{
Political Aid Cycles
}

\author{
By Michael Faye and Paul Niehaus
}

\section{Web Appendix}

This Appendix examines the robustness of the results presented in the main text along two dimensions. Section A.A1 explores potential mis-specification issues arising due to the granular timing of aid flows and elections, and Section A.A2 examines the sensitivity of the results to methods for limiting the influence of outliers.

\section{A1. Timing Concerns}

One limitation of our data is that we observe both elections and aid flows at the annual level. This raises a question whether the relationship between aid and UN alignment during election years is driven by aid before or after the election itself takes place. The Palestinian anecdote cited in the Introduction and our own conversations with former USAID officials suggest that donors can implement new aid packages fairly quickly before an election if they desire, but it is desirable to examine the issue more systematically.

Specifications Exploiting Election Timing. One way we can examine this issue is to exploit information on the timing of elections, which is available for 268 out of the 274 elections in our sample. If aid cycles were driven by changes in aid following elections we would expect to see stronger effects for earlier elections, while our influence hypothesis predicts stronger effects in later elections. Table A.1 reports results differentiated by election timing. In the first column we define an election as "early" if it took place in the first six months of the year (the median election takes place in July). We estimate larger aid cycles for elections that take place later in the year, but economically and statistically significant cycles around early elections as well. In the next column we redefine "early" to mean taking place in the first three months of the year; using that definition we again estimate a large and significant effect of later elections but now estimate a small and insignificant cycle for early elections.

Specifications Using Aid Disbursements. Our primary estimates of political aid cycles use aid commitments as the outcome variable, but we could alternatively have used aid disbursements, which are recorded separately in the DAC database. The quantitative gap between commitments and disbursements is not large in our sample (mean disbursements are $\$ 50$ million, as opposed to mean commitments of $\$ 57$ million), but the difference in the timing of commitments and disbursements could be important depending on the nature of political 
aid cycles. If one believes that donors are signalling support for an incumbent then commitments are appropriate (especially since we know that they are not binding). If, on the other hand, one thinks that fiscal policy is the key mechanism then either commitments or disbursements might be appropriate depending on the incumbent's ability to spend future income. To examine this issue we re-ran our main estimators using aid disbursements rather than commitments as the outcome variable. The results are reported in Tables A.2 and A.3. Estimated political cycles in aid disbursements are smaller than estimated cycles in commitments, but they remain economically and statistically significant.

\section{A2. Robustness to Outliers}

Table A.4 presents summary statistics on ODA by recipient for our sample. As is well-known this distribution is skewed, with politically important countries receiving disproportionate shares of total ODA. Given this skewness, one important question is how sensitive the results are to outliers.

Dropping Individual Observations. A simple way to define "outliers" is to identify individual outlier observations. Figure A1 plots the residual values of ODA and UN alignment, separately for election and non-election years, after taking out donor-recipient means. The three data points identified in red are obvious outliers (these are US aid to Egypt in 1990 and 1991 and Japanese aid to Pakistan in 2003). To verify that our results are not driven by these observations we re-ran our main specification including a separate indicator variable for each of these three observations, effectively dropping them from the regression. Table A.5 reports the results; dropping these outliers reduces the estimated magnitude of aid cycles but they remain economically and statistically significant.

Dropping Large Recipients. An alternative notion of robustness is sensitivity to large aid recipients. Tables A.6 and A.7 report estimates of our main specifications for samples that exclude the largest 3 recipients (Egypt, Indonesia, India) and largest 5 recipients (Egypt, Indonesia, India, Israel, China) in our sample, respectively. The estimates in Table A.6 are smaller in magnitude but qualitatively similar and in fact more strongly significant than baseline estimates. Estimates in Table A.7 are again somewhat smaller in magnitude but remain qualitatively consistent with baseline estimates and statistically significant (in some cases at the 10 percent level). ${ }^{1}$

Estimates Using Ln(ODA) as the Dependent Variable. An alternative way to reduce the weight given to larger aid recipients is to estimates specifications using the logarithm of ODA as the dependent variable. A priori it is unclear whether estimation in logs or in levels is more appropriate. Suppose the optimal amount of aid given to recipient $r$ during "normal" years is $n_{r}$ while the magnitude of the "adjustment" in aid flows a donor wishes to make prior to an election in

\footnotetext{
${ }^{1}$ We also estimated models dropping each individual recipient one-at-a-time. None of the exclusions has a material effect on the results except excluding Egypt; excluding Egypt yields estimates similar to those in Table A.6.
} 
recipient $r$ is $e_{r}$. If cross-recipient variation in these figures is proportionate - i.e. if $e_{r}=k n_{r}$ for some constant $k$ - then a logarithmic specification is appropriate. On the other hand if $e_{r}$ is independent of $n_{r}$ then a linear model is appropriate. It is thus an empirical question which specification better fits the data.

An additional issue that arises when fitting models for log ODA is that aid flows are strictly positive for only 90 percent of the donor-recipient-year observations in our sample. Following Kuziemko \& Werker (2006) we set ODA to $\$ 1$ for the remaining observations and then take natural logarithms. Table A.8 presents results, replicating the specifications used in Tables A.6 and A.7. In general the estimates are consistent in sign and order of magnitude with those in levels. While they are less precisely estimated, we do obtain significant results when we isolate the role of bilateral UN alignment in Column V and perhaps most importantly when we focus on elections after the 3rd month of the year in Column IX. (Recall from Table A.1 that we obtain significant results in levels only for these elections.) 
Table A.1-Political Aid Cycles Differentiated by Election Timing

\begin{tabular}{lll}
\hline \hline Regressor & Early = First 6 Months & Early = First 3 Months \\
\hline Early Election & -13.189 & -1.771 \\
& $(1.582)^{* * *}$ & $(8.673)$ \\
UN * Early Election & 25.946 & 3.316 \\
& $(0.000)^{* * *}$ & $(14.401)$ \\
Late Election & -41.154 & -34.746 \\
& $(14.828)^{* * *}$ & $(10.593)^{* * *}$ \\
UN * Late Election & 66.942 & 58.400 \\
& $(29.595)^{* *}$ & $(20.865)^{* * *}$ \\
UN Alignment & -31.402 & -31.396 \\
& $(21.384)$ & $(21.493)$ \\
$\mathrm{N}$ & 14435 & 14435 \\
$R^{2}$ & 0.001 & 0.001 \\
\hline
\end{tabular}
significance is denoted as: ${ }^{*} p<0.10,{ }^{* *} p<0.05,{ }^{* * *} p<0.01$ 


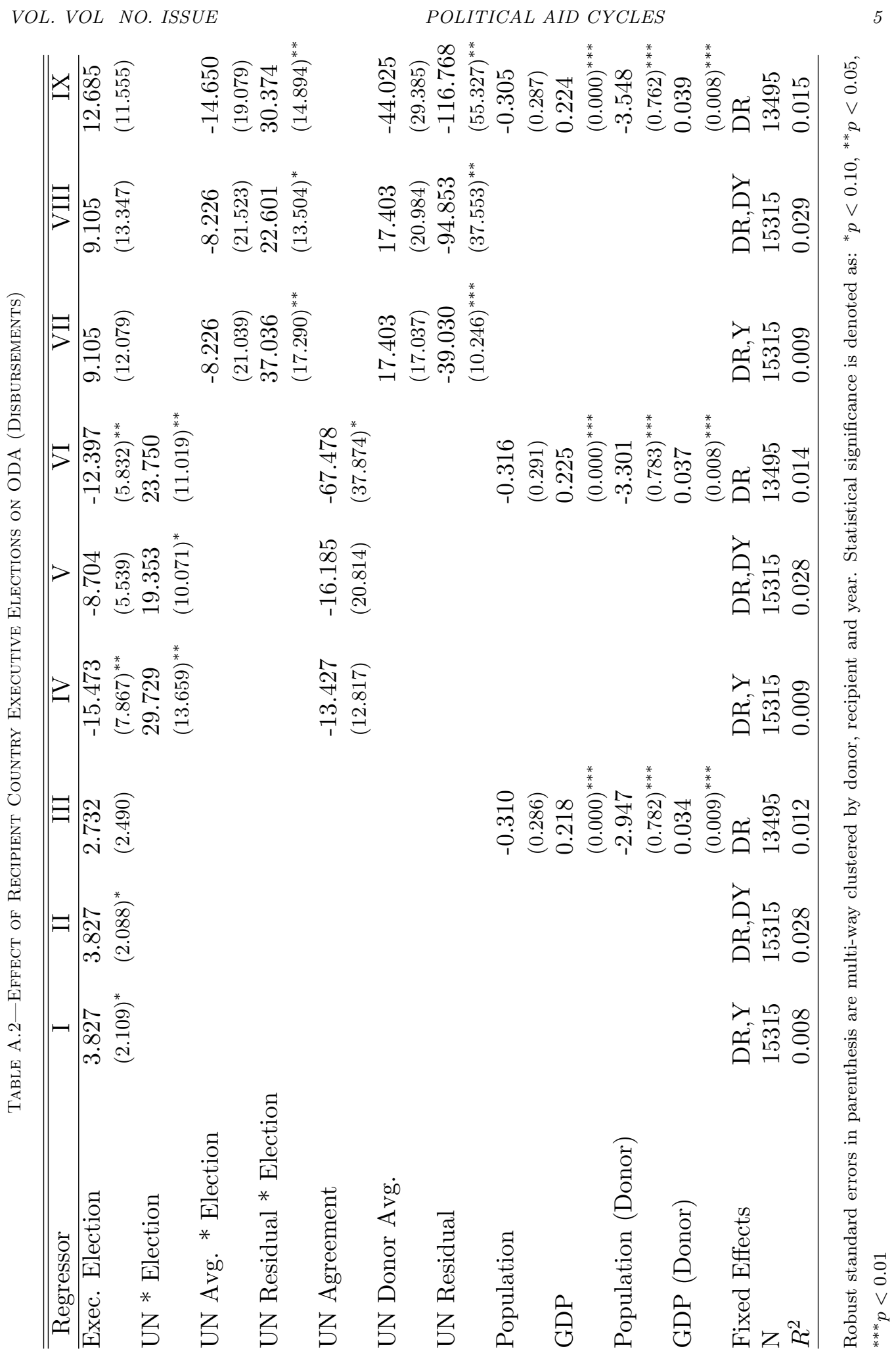


Table A.4-ODA by Recipient

\begin{tabular}{|c|c|c|c|c|c|c|c|c|}
\hline Recip. & Total ODA & Mean ODA & Recip. & Total ODA & Mean ODA & Recip. & Total ODA & Mean ODA \\
\hline EGY & 88,791 & 592 & NIC & 5,800 & 39 & GUY & 1,417 & $\begin{array}{l}- \\
\end{array}$ \\
\hline IDN & 62,303 & 415 & BFA & 5,583 & 37 & PNG & 1,404 & 9 \\
\hline IND & 55,391 & 369 & UGA & 5,274 & 35 & ALB & 1,260 & 15 \\
\hline ISR & 46,502 & 423 & ZWE & 5,164 & 41 & AZE & 1,050 & 17 \\
\hline $\mathrm{CHN}$ & 45,945 & 353 & HTI & 5,019 & 33 & SWZ & 1,046 & 7 \\
\hline PAK & 33,704 & 225 & YEM & 4,610 & 31 & NAM & 998 & 14 \\
\hline PHL & 32,842 & 219 & JAM & 4,481 & 30 & CPV & 948 & 7 \\
\hline BGD & 29,857 & 199 & SYR & 4,390 & 29 & MKD & 898 & 15 \\
\hline THA & 26,370 & 176 & GTM & 4,373 & 29 & VEN & 861 & 6 \\
\hline TUR & 20,039 & 134 & GIN & 4,192 & 28 & SGP & 854 & 8 \\
\hline MAR & 17,360 & 116 & COG & 4,066 & 27 & URY & 809 & 5 \\
\hline LKA & 13,931 & 93 & RWA & 4,065 & 27 & FJI & 806 & 5 \\
\hline CIV & 13,820 & 92 & NGA & 3,988 & 27 & PRK & 712 & 10 \\
\hline VNM & 13,247 & 95 & $\mathrm{ECU}$ & 3,920 & 26 & CYP & 706 & 6 \\
\hline KEN & 12,810 & 85 & CRI & 3,829 & 26 & ERI & 677 & 12 \\
\hline TZA & 12,241 & 82 & GAB & 3,809 & 25 & SAU & 622 & 4 \\
\hline PER & 12,195 & 81 & BEN & 3,516 & 23 & HRV & 573 & 9 \\
\hline MYS & 12,171 & 81 & CHL & 3,377 & 23 & OMN & 553 & 4 \\
\hline CMR & 11,701 & 78 & TGO & 3,374 & 22 & BLZ & 537 & 5 \\
\hline JOR & 11,634 & 78 & PRY & 3,014 & 20 & SLB & 530 & 4 \\
\hline SEN & 11,271 & 75 & IRN & 2,835 & 19 & MDA & 496 & 12 \\
\hline BOL & 10,878 & 73 & ZAF & 2,610 & 47 & WSM & 398 & 3 \\
\hline TUN & 10,832 & 72 & SOM & 2,550 & 30 & BTN & 332 & 2 \\
\hline GHA & 9,933 & 66 & LBN & 2,445 & 16 & MDV & 320 & 2 \\
\hline BRA & 9,852 & 66 & AGO & 2,175 & 15 & ARE & 314 & 3 \\
\hline SDN & 9,621 & 64 & BWA & 2,166 & 14 & TKM & 235 & 4 \\
\hline ZMB & 9,381 & 63 & LAO & 2,126 & 14 & LCA & 213 & 2 \\
\hline SLV & 8,194 & 55 & SLE & 2,095 & 14 & CUB & 212 & 1 \\
\hline MMR & 8,067 & 54 & ARG & 2,081 & 14 & MLT & 211 & 2 \\
\hline MOZ & 8,016 & 55 & DJI & 1,977 & 15 & SUR & 119 & 1 \\
\hline ETH & 7,747 & 52 & KOR & 1,966 & 44 & KWT & 100 & 1 \\
\hline COL & 7,675 & 51 & KAZ & 1,839 & 28 & BRB & 81 & 1 \\
\hline MLI & 7,215 & 48 & MNG & 1,796 & 18 & BHR & 68 & 0 \\
\hline MEX & 7,179 & 48 & PAN & 1,747 & 12 & SVN & 68 & 1 \\
\hline MDG & 7,022 & 47 & LSO & 1,665 & 11 & LBY & 62 & 0 \\
\hline HND & 6,592 & 44 & MUS & 1,602 & 11 & BRN & 50 & 1 \\
\hline DZA & 6,490 & 43 & GEO & 1,540 & 26 & QAT & 30 & 0 \\
\hline NPL & 6,214 & 41 & ARM & 1,518 & 25 & BHS & 13 & 0 \\
\hline MWI & 6,180 & 41 & AFG & 1,510 & 12 & & & \\
\hline
\end{tabular}


Figure A1. OutLiers

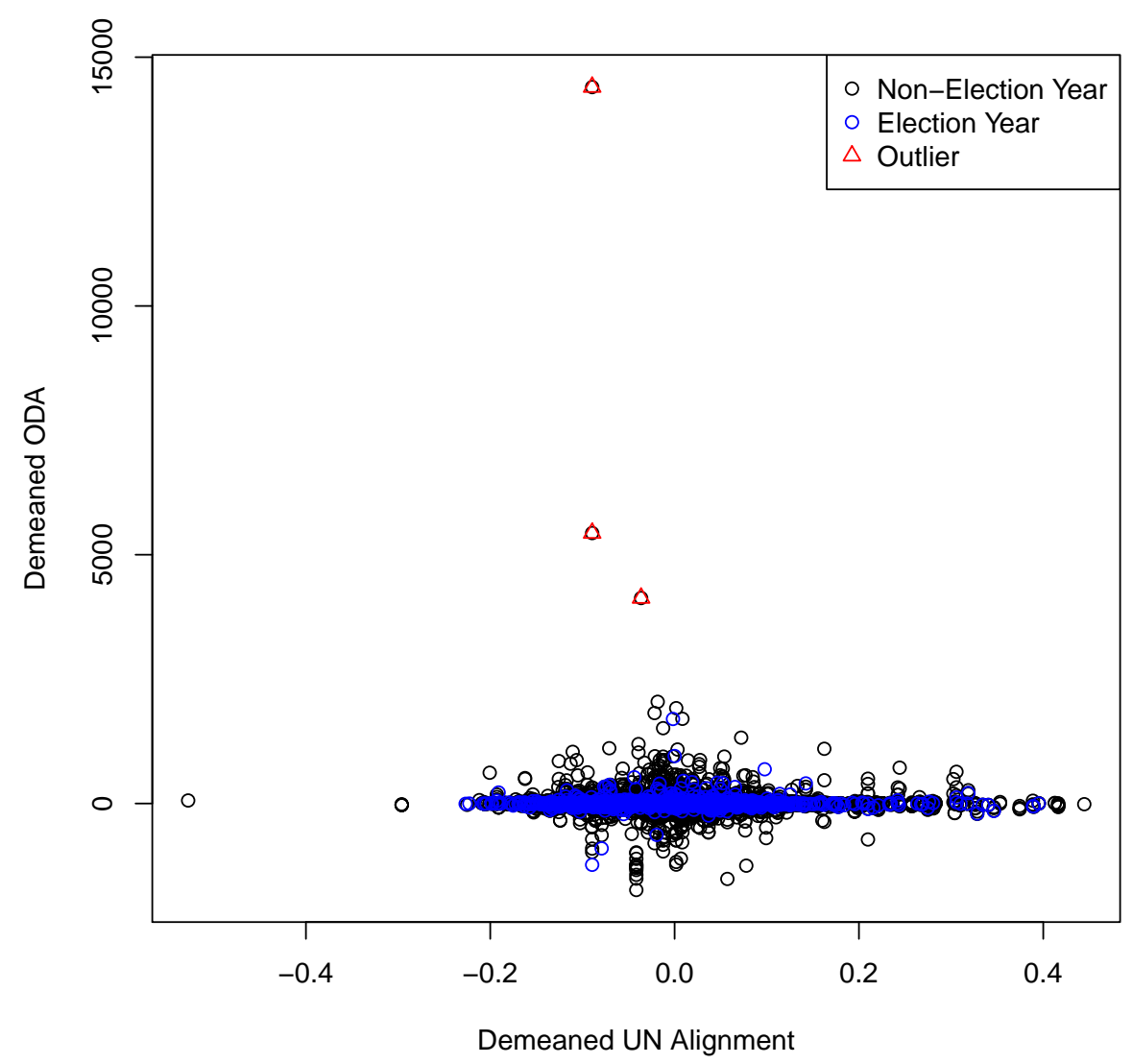


Table A.5-Political Aid Cycles Controlling for Outliers

\begin{tabular}{ll}
\hline \hline Regressor & \multicolumn{1}{c}{ I } \\
\hline Exec. Election & -13.390 \\
UN * Election & $(7.256)^{*}$ \\
& 26.250 \\
UN Agreement & $(12.394)^{* *}$ \\
& 8.886 \\
Fixed Effects & $(17.268)$ \\
$N$ & DR,Y,Outliers \\
$R^{2}$ & 15315 \\
\hline
\end{tabular}

Robust standard errors in parenthesis are multi-way clustered by donor, recipient and year. Statistical significance is denoted as: ${ }^{*} p<0.10,{ }^{* *} p<0.05,{ }^{* * *} p<0.01$ 


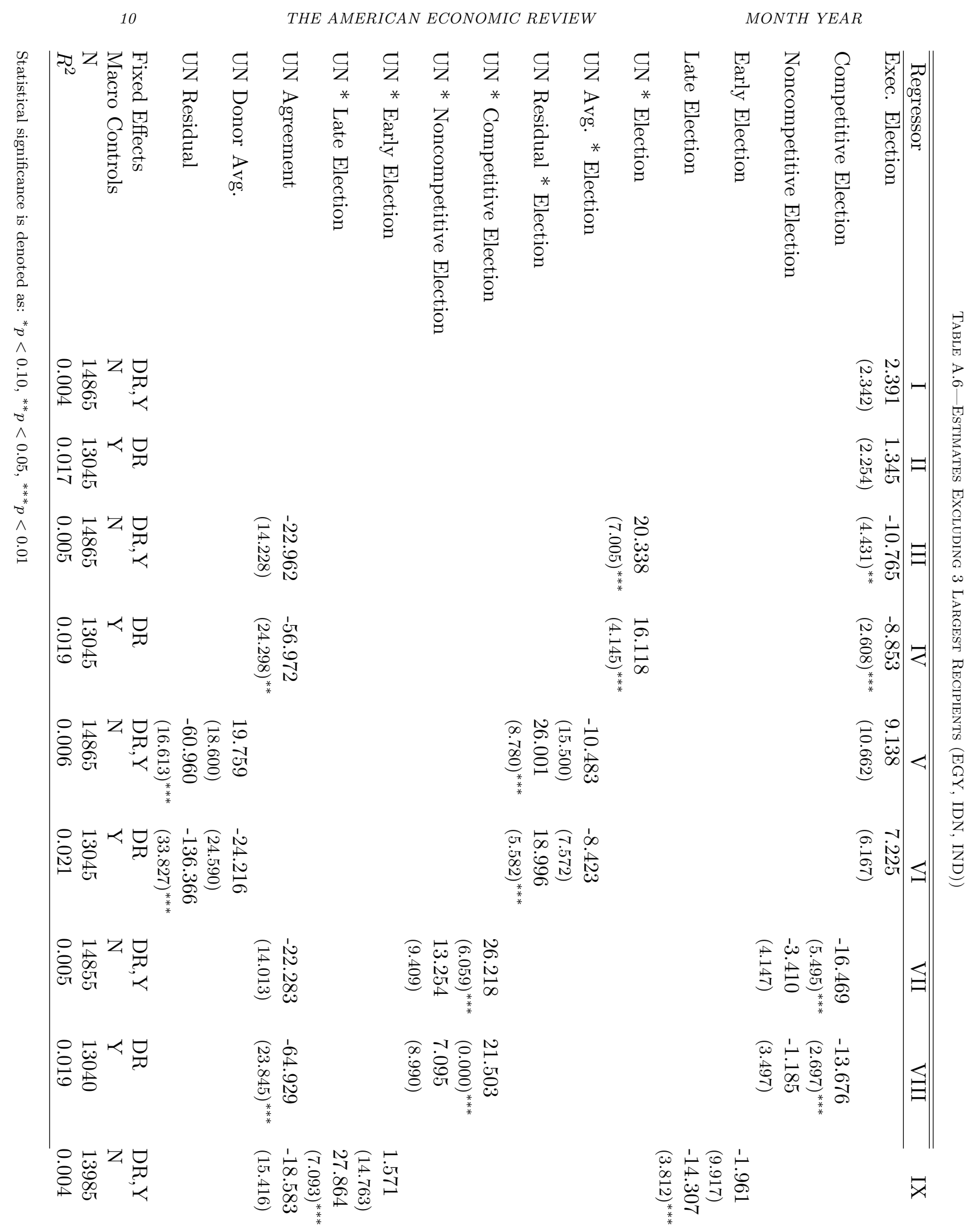




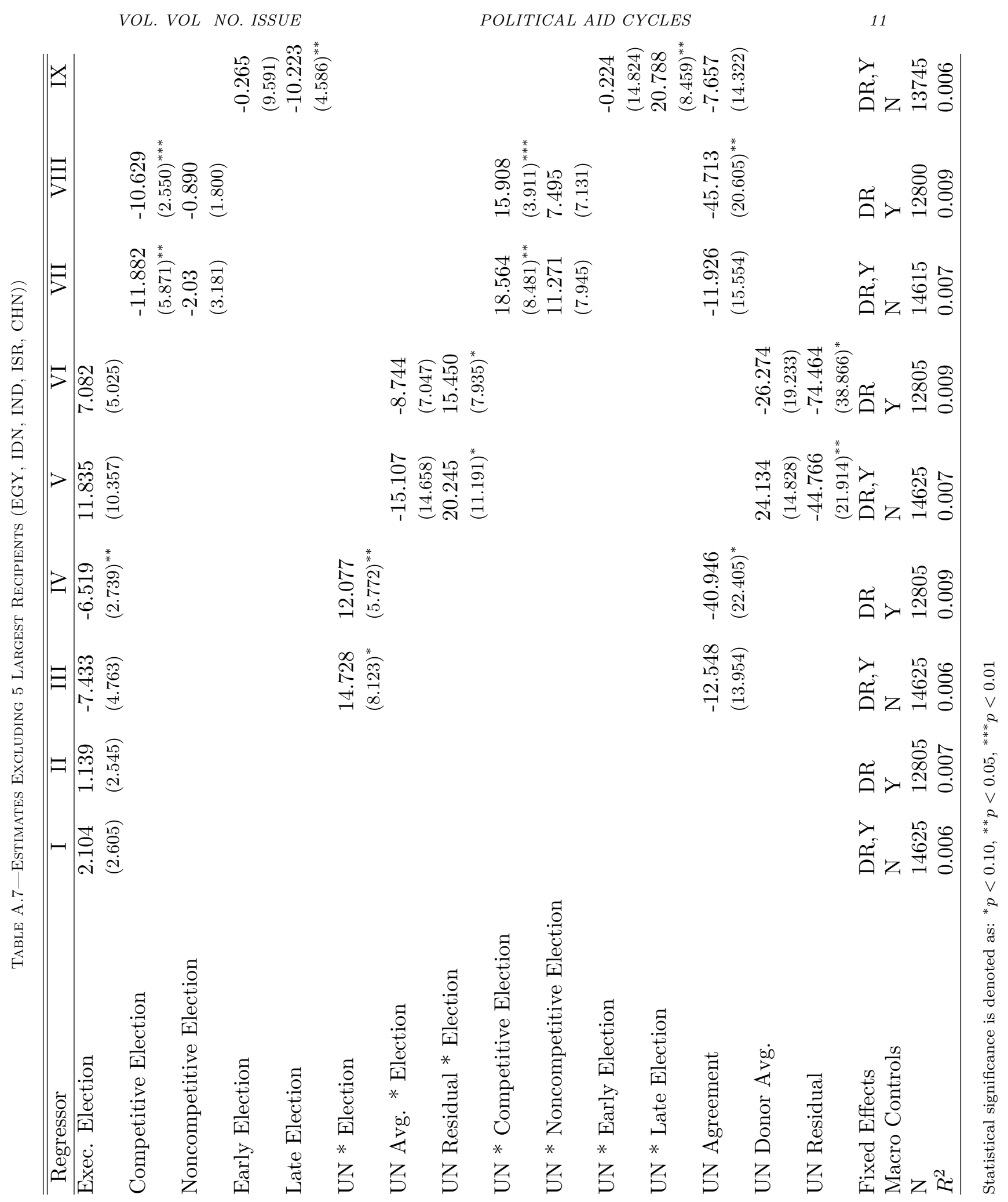




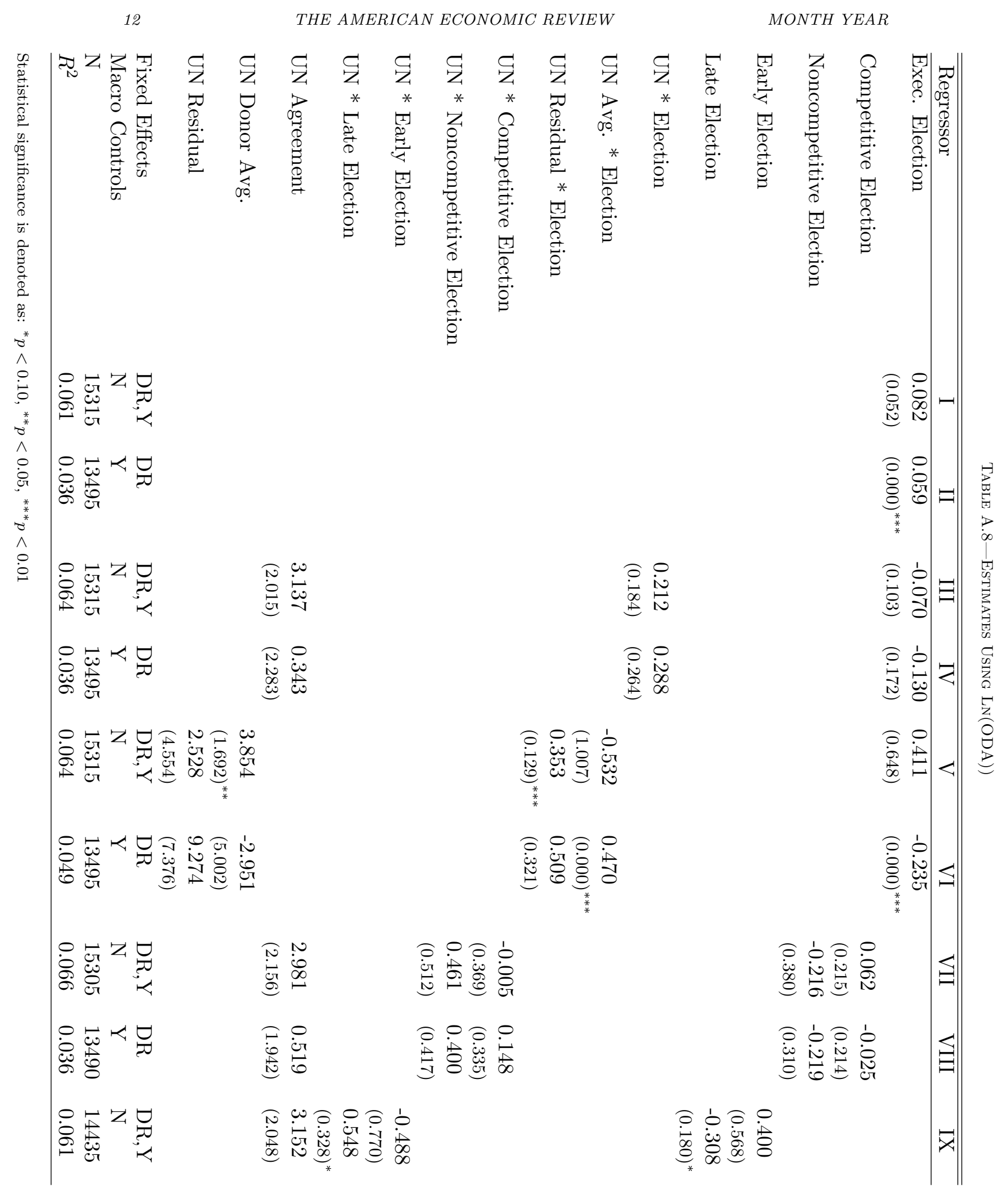

